\title{
De França para o Brasil - A Literatura Portuguesa a agradecer
}

\author{
From France to Brasil - Portuguese Literature \\ Feels Grateful
}

Irene Fialho

CLP- Universidade de Coimbra

\section{DoI}

https://doi.org/10.37508/rcl.2021.n46a438

\section{RESUMO}

Em 1884 Mariano Pina escrevia nas páginas da Gazeta de Notícias do Rio de Janeiro, jornal de que era correspondente em Paris, um artigo dedicado a Eça de Queirós. Escondidas sob a aparente forma de uma crónica banal, versando o encontro de dois amigos, nela encontramos informações relevantes, esclarecedoras de factos desconhecidos da vida e da obra do romancista português.

Palavras-Chave: Eça de Queirós; Alves E C. a; Mariano Pina; Gazeta de Notícias; pug.

\section{Abstract}

In 1884, Mariano Pina, a Portuguese journalist, wrote in Rio de Janeiro's newspaper Gazeta de Notícias, a chronicle about a meeting with Eça de Queiroz, epitome of Portuguese Literary Realism. The description of that meeting and talk reveals facts about the Portuguese novelist life and oeuvre, ambiguous until now.

KeYWORDS: Eça de Queirós; Alves $\mathcal{E}$ C.a; The Yellow Sopha; Mariano Pina; Gazeta de Notícias; pug. 
A crónica que a seguir se apresenta foi publicada n' A Gazeta de Notícias do Rio de Janeiro em Abril de 1884 e reeditada no século XX no terceiro volume de Polémicas de Eça de Queiroz, com organização, introdução e notas de João C. Reis. Este autor, porém, editou o folhetim de Mariano Pina, correspondente português da Gazeta em Paris, enquanto “contraponto” encomiástico de Eça de Queirós, aos textos assinados por Ramalho Ortigão e também publicados na sua antologia, não enunciando ou apontando informações essenciais para a história da vida e da obra do autor de Os Maias referidas no texto, e que aqui se pretendem lembrar. ${ }^{1}$

Recordemos que o intercâmbio mediático entre a Europa e a América iniciou-se no século XIX, com as novas invenções trazidas pela Revolução Industrial, permitindo a rápida impressão a vapor, e o rápido transporte nos navios-vapores, dos jornais e revistas que passaram a circular entre os dois continentes. No caso de Portugal e do Brasil, unidos pela língua e outras expressões culturais, encontramos num e no outro país, por parte dos donos e diretores dos periódicos, interesse em publicar matérias que apelassem à curiosidade dos leitores de ambos os lados do Atlântico pois que, aumentando as tiragens, aumentavam também os lucros das vendas. Para tanto contratavam correspondentes, publicistas, escritores de notícias, de artigos, de locais, com carreira reconhecida; grande parte deles era recrutada entre portugueses ou brasileiros habitantes em países terceiros ou enviados expressamente para as grandes

1 V. Polémicas de Eça de Queiroz - 1874-1887 - vol. III (Organização, Introdução e Notas de João C. Reis). Odivelas: Heuris, 1987. Tenha-se em conta que o organizador aponta dois outros lugares de publicação que não coincidem com a Gazeta de notícias: a ilustração, de Paris, e o Diário da manhã, de Lisboa; não tendo sido possível consultar este último título, procurou-se em vão na revista publicada em França. 
capitais para narrarem em crónica os acontecimentos marcantes que podiam interessar ao público longínquo.

Como é bem sabido, a Gazeta de Notícias do Rio de Janeiro, fundada em 1875, contou desde cedo com a colaboração de autores portugueses muito populares no Brasil, como Pinheiro Chagas e Ramalho Ortigão e, a partir da década de 1880, alargou as suas colaborações no exterior, recorrendo habitualmente a nomes consagrados do jornalismo e da literatura. Foi esse o caso do português Guilherme de Azevedo, colaborador assíduo nas publicações de Rafael Bordalo Pinheiro e em variadíssimos jornais portugueses, convidado em 1880 pela Direção da Gazeta para ser o correspondente do jornal carioca em Paris, cidade para onde foi viver. De saúde frágil, Azevedo viria a morrer na capital francesa dois anos mais tarde e seria substituído por Mariano Pina, um jovem que então contava apenas vinte e dois anos mas, tinha já bastante experiência no jornalismo, a ponto de ser recomendado para o cargo pelo veterano Pinheiro Chagas, com quem já colaborara. ${ }^{2}$

A Mariano Pina, que então se fixou em Paris, cabia escrever, segundo o acertado com o editor do jornal, Henrique Chaves, os artigos noticiosos não assinados intitulados "Correio de França” e umas “Crónicas de Paris", que podiam ser assinadas, além de material variado que pudesse servir a Gazeta. ${ }^{3}$ Com o decorrer do tempo, o "Correio de França” ganhou assinatura através das iniciais “M.P.” e do desenvolvimento "M. Pina” ainda nesse ano de 1882, e as Crónicas, com o título "Quadros de Paris", surgidas no rodapé do jornal, mereciam o nome completo do autor, que mais tarde seria aceite também no "Correio de França".

2 V. Luca, Tânia Regina. A ilustração (1884-1892) - Circulação de textos e imagens entre Paris, Lisboa e Rio de Janeiro. São Paulo: UNESP, 2018.

3 V. Miné, Elza. "Mariano Pina, a Gazeta de Notícias e a Ilustração: histórias de bastidores contadas pelo seu espólio”. Revista da Biblioteca Nacional, julho-dezembro de 1992, p. 44 
Dois anos depois do início da sua correspondência para a Gazeta, em 1884, Mariano Pina seria abordado por Elísio Mendes, um dos proprietários da publicação do Rio de Janeiro, para intentar nova aventura em Paris: criar e dirigir uma revista ilustrada, tão ao gosto da novidade na época, quando a gravura impressa se tornava simultaneamente mais nítida e menos dispendiosa e, por exemplo, em França se publicava L'Illustration e em Inglaterra a Illustrated London news, seguidas, por exemplo, pela portuguesa O Ocidente. Neste caso a revista completaria os objetivos de divulgação da empresa do popular jornal carioca, pois tinha como público-alvo as classes mais cultas de Portugal e do Brasil. ${ }^{4}$ Pina tinha a seu encargo garantir a boa qualidade das gravuras e da impressão, mas também a escolha e orientação dos colaboradores da revista. Nos primeiros casos, o fato de a revista ser concebida em Paris facilitava a tarefa ao seu diretor, pois na cidade-luz Pina tinha acesso a boas estampas, criadas para outras publicações, o que lhe dava a vantagem de poder pagar preços menos elevados pelos direitos da sua utilização, contando também com tipografias modernas e bem equipadas que facilitavam o trabalho de impressão. Quanto aos colaboradores, a sua carreira jornalística, a que hoje chamaríamos precoce - Mariano Pina estreou-se nos jornais aos 18 anos... -, era uma mais-valia, pois conhecera em Lisboa muitos dos grandes vultos da política, do jornalismo, das artes e da literatura, com os quais contactaria para participarem na nova empresa. Entre eles contava-se Eça de Queirós, também ele colaborador da Gazeta de notícias.

Responsável pelo consulado de Portugal em Bristol, Eça estreou-se na Gazeta em 24 de Julho de 1880 com um folhetim encabeçado

4 Sobre a relação de pertença da Ilustração à empresa da Gazeta de Notícias vejam-se os trabalhos de Tânia Regina de Luca, nomeadamente A Ilustração (1884-1892) - Circulação de textos e imagens entre Paris, Lisboa e Rio de Janeiro. São Paulo: UNESP, 2018. 
"Cartas de Paris e Londres": o jornal incumbira-o de fazer a correspondência de Inglaterra e, em lugar do falecido Guilherme de Azevedo, enquanto este não tinha substituto definitivo, também a correspondência francesa. Dava-se o caso de o cônsul português passar parte do ano na cidade de Angers, França, de onde enviava os seus textos para a Gazeta de Notícias e onde, a partir de 1882, estava mais próximo de Mariano Pina. Na crónica que se segue, Pina refere ter-se cruzado com Eça em Lisboa, no restaurante Augusto, localizado à época na atual travessa da Trindade, ao Chiado, pelo que o conhecimento de ambos deve ter acontecido antes da partida de Pina para Paris; ocorreu, decerto, antes de 1882, pois data desse ano a primeira missiva conhecida do romancista português para o jornalista, missiva onde transparece familiaridade entre ambos. ${ }^{5}$

É por uma outra carta de Eça de Queirós ao amigo, datada de quatro de Março de 1884 e endereçada de Angers, que ficamos a saber que o romancista estivera dias antes em Paris com Pina e um outro português, Lourenço Malheiro. Terá sido nessa ocasião que Mariano Pina falou com Eça a respeito da nova revista que preparava, e que já tinha título - A Ilustração - e esboço de prospeto. O autor de Os Maias, em nova carta, de 26 de Março, aconselha-o a tirar proveito do folheto para atrair o público luso e brasileiro:

(...) Você no prospeto devia prometer também vistas de Portugal e Brasil, ilustrações do[s] sucessos passados nesses países onde não sucede nada, e retratos dos seus grandes homens. O burguês d'aquém e d'além mar - gosta sobretudo de bonecos que digam respeito ao seu bairro. (QUEIRÓS, 2008, p. 328-329).

5 As cartas de Eça para Pina, encontrando-se ambos, por esse tempo, em França, tomam contornos quase anedócticos, com pedidos do romancista ao jornalista para que este lhe enviasse objetos banais e inusitados, como um aparelho de ginástica e frascos de verniz para sapatos. 
Acrescentava: "Eu estou às ordens, para um pequeno artiguinho" (QUEIRÓS, 2008, p.329).

O primeiro número d'A Ilustração: revista quinzenal para Portugal e Brasil veio a público em 5 de Maio de 1884 e estampava, a página 3, um "Aviso":

Para que os nossos leitores possam julgar do quanto desejamos dar a maior atualidade e o maior interesse à Ilustração, anunciamos-lhe desde já, para um dos próximos números, a colaboração especial do ilustre romancista português - Eça de Queirós - um dos escritores que mais simpatias possui em Portugal e Brasil.

No número seguinte, de 20 de Maio, novo "Aviso" referia que a revista tinha já em seu poder "o original do primeiro trabalho escrito expressamente para a Ilustração pelo ilustre romancista português - Eça de Queirós - um trabalho originalíssimo (...)", levantando o véu relativamente ao assunto versado no artigo, cujo tema inusitado abriria o apetite aos leitores para adquirirem a revista, mas também acrescentando as razões, oficiosas ou oficiais, para a permanência numa estância francesa, de um funcionário que o governo português colocara no consulado de Bristol, no outro lado do canal da Mancha: ${ }^{6}$

Eça de Queirós que se acha atualmente numa terra de França, em Angers, por motivo de saúde, tem consigo um cão, um soberbo pug, que se chama D. José. Em Bristol, em casa do romancista, ficou um outro animal, a gata Pussy. Ora é exatamente uma carta de D. José à sua amiga Pussy o que Eça de Queirós nos envia, carta que tem por título - A Inglaterra e a França julgadas por um inglês. - Este trabalho do eminente romancista, que nós devemos à

6 A este respeito leia-se o romance de José Augusto França, A bela angevina. Lisboa: Presença, 2005. 
muita simpatia e à muita estima que lhe inspira a Ilustração, será publicado no próximo número, no número que há de aparecer em Paris no dia 5 de Junho.?

De facto, o número 3 da revista imprimia um artiguinho assinado por Eça de Queirós, “A Inglaterra e a França - julgadas por um inglês” escrito em “Angers, Maio” - conforme indicação autógrafa; a data do manuscrito, escrita por outra mão, “14 Mai 84”, é possivelmente a da entrada na tipografia. ${ }^{8}$

O texto divide-se em duas partes: uma introdução, do narrador principal, identificável com Eça de Queirós, contando a história de uma raça de cães - os pug (em inglês) ou carlin (em francês) - a conclusão irónica dessa história, endereçada aos jornais ingleses e, entre as duas, uma carta ficcional e fantasiosa escrita por uma personagem prosopopaica - o cão D. José - e dirigida a uma outra personagem, também ela personificada - a gata Pussy - animais de estimação do narrador, tal como contado no segundo número da revista.

O artigo, incluindo a carta, é um pretexto de Eça de Queirós para tecer considerações respeitantes a diferenças entre os dois países -

7 Pina continuará a explorar a estada de Eça de França, bem como os momentos de encontro em Paris, quando Eça de Queirós deixava momentaneamente o Anjou (onde estanciou entre Março e Maio de 1884, além de outras vilegiaturas), escudando o amigo atrás do débil estado de saúde que, no entanto, lhe permitia continuar a escrever obras de arte, caso de "Um Passeio a Sintra", de Os Maias, que teve pré-publicação em A Ilustração, a par de outros trechos do mesmo romance.

$8 \mathrm{O}$ artigo foi publicado postumamente na antologia Notas Contemporâneas, de 1909, volume organizado por Luís de Magalhães e ultimamente em Almanaques e outros dispersos, edição crítica de Irene Fialho. O manuscrito autógrafo encontra-se depositado no Arquivo de Literatura Portuguesa Contemporânea da Biblioteca Nacional de Portugal, no espólio dos irmãos Augusto e Mariano Pina, sob a cota N17/129. 
Inglaterra e França - e às suas sociedades, políticas, culturas e costumes. Porém, na carta, e como conviria à personificação, as comparações não excedem limites muito básicos, correspondendo aos alvos da inteligência de D. José, o cão, que vai escudando os seus comentários com as opiniões banais e os lugares-comuns de um repórter do jornal britânico The Times, o, assim chamado, Amigo da imparcialidade. Este opinion maker, modelado no publicista inglês da era vitoriana, aquele que encontrava partidários nos seus leitores enquanto formulador de verdades supostamente inquestionáveis é, afinal, o objeto de crítica visado pelo narrador principal, que não poupa na ironia, classificando-o, por meio da voz do animal, com adjetivos laudatórios enquanto põe em questão o seu discernimento. Por outro lado, e acrescentando, Orlando Grossegesse considera que Eça traçou neste artigo

(...) a evolução histórica do dandi, transposta para o nível animal: D. José é um cão dândi, que, nas suas observações sobre a Inglaterra e a França, mostra uma atitude dandistica face ao mundo social e cultural, queixando-se da "mesmice" e "monotonia intolerável” em Inglaterra e louvando a originalidade na França. (GROSSEGESSE, 2015, 104).

O mesmo autor observa que "O cão $D$. José parece uma espécie de autorretrato grotesco do escritor José Maria Eça de Queirós (ainda a identidade parcial do nome é notável) que sempre sentiu atração pelo dandismo" (GROSSEGESSE, 2015, 104).

No entanto, não é este artigo, estudado por Grossegesse em “O animal filosófico e a escrita autobiográfica", que aqui nos traz, mas sim o texto de Mariano Pina, publicado na Gazeta de Notícias em 12 de abril do mesmo ano de 1884, mas escrito em Paris no dia 20 de março anterior, ou seja, pouco depois do seu encontro com Eça de Queirós na capital francesa. Trata-se de um "Correio de França” e nele, Pina, como faria frequentemente na Ilustração, refere-se a Eça de Queirós 
com um discurso próprio da admiração de um jovem perante um escritor mais velho e consagrado - relação simbiótica, se pensarmos que ambos escreviam para o mesmo jornal cuja firma era também proprietária da revista que em breve sairia com textos dos dois... apresentando entusiasticamente aos leitores da Gazeta o temperamento positivo do popular autor. O correspondente em Paris chama a atenção para a débil forma física de Eça, para a necessidade de, por questões de fraqueza corporal, ele ter de se recolher a Angers, mas também para as qualidades de elegância do dândi recém chegado de Londres com uma “(...) grande mala de couro, profundamente inglesa e profundamente forte (...)", como refere noutro artigo de $A$ Ilustração, datado de 20 de Junho.

Depois, e todos os amigos de Eça de Queirós eram unânimes quanto ao tema, explica o método de trabalho e os horários de refeições do romancista, causas prováveis da ruína da sua saúde quando, em Lisboa, escrevia e simultaneamente mergulhava na vida boémia. Parece que em Inglaterra Eça se teria redimido, por meio de dietas, de sport e de uma vida regrada, mas, sanado do corpo, estragara os nervos, e só em França poderia recuperar o bem-estar psicológico... O restante texto gira em torno de informações semelhantes às de muitos outros artigos sobre o romancista. No entanto, este "Correio de Paris", crónica esquecida e particamente desconhecida do público queirosiano, revela duas informações relevantes para os estudos queirosianos.

Logo no início da crónica, e meses antes do “Aviso" d’ A ilustração, ou seja, antes de ter recebido a proposta de Eça para o texto e, depois, o manuscrito do artigo, Mariano Pina refere o cão com que Eça apareceu, e se passeou, em Paris: tal como em "A Inglaterra e a França...”, D. José é de raça pug, “pequeno e atarracado”, cor de chocolate - tipo raro na época, por ser criação de cruzamento muito recente, o que justificaria ser irmão de um pug semelhante, chamado Mops, pertencente à Princesa de Gales, a futura rainha Alexandra, animal 
que efetivamente existiu e efetivamente foi premiado num concurso canino, tal como Pina menciona no seu texto. Se eram verdadeiros os sucessos de D. José perante as senhoras francesas, tal como os menciona Mariano Pina, não o eram menos quando glosados por Eça de Queirós no texto da Ilustração. A fantasia de Eça - inspirada por Pina? - baseou-se humoristicamente num ser que lhe era próximo, cuja personalidade animal era sua conhecida, cujas reações podia observar e descrever.

Porém, não menos importante para o estudo da obra de Eça de Queirós, são os esclarecimentos que esta crónica, perdida nas páginas da Gazeta de Notícias, fornece relativamente à novela intitulada Alves \& Cia.

Quando, em 1994, surgiu a edição crítica de Alves $\mathcal{E}$ C. ${ }^{a}$, existiam ainda muitas dúvidas quanto à data de escrita do pequeno romance e quanto à autenticidade seu título. Eça não deixou na sua correspondência qualquer menção a esta obra. Em 1924, o autógrafo original foi encontrado no famoso baú de ferro que continha os manuscritos trazidos de França após a morte do escritor: os seus filhos, que seriam também os primeiros editores desses textos, devem ter-se deparado com os mesmos problemas de datação e designação. Devido à conhecida manipulação das narrativas queirosianas por parte de quem primeiro as editou, acreditou-se que a atribuição do título Alves $\mathcal{E} C{ }^{a}{ }^{a}$ seria apócrifa, pois não existiam testemunhos credíveis que o pudessem confirmar. Podemos agora, finalmente, assegurar que Alves $\mathcal{E} C$. $^{a}$ foi, desde o início, o nome escolhido por Eça de Queirós para esse texto, tantas vezes considerado menor pela crítica. Mais, através da crónica de Mariano Pina, ficamos a saber que a novela destinava-se a ser publicada na Gazeta de Notícias, por ter sido encomendado pelo fundador do jornal, Ferreira de Araújo, para surgir no espaço do Folhetim.

Finalmente, o artigo esclarece a questão da data de escrita da novela: o manuscrito autógrafo apresenta no papel a marca de água 
de 1883 , pelo que se sabia que não poderia ter sido composto antes desse ano, se bem que a encomenda de Ferreira de Araújo, sabe-se agora, tenha sido feita em 1882. Foi levantada a hipótese de ser um escrito de 1887 , hipótese baseada numa representação nesse ano da ópera L'Africaine de Meyerbeer, no teatro de S. Carlos em Lisboa, à qual Eça teria assistido e que estaria ainda fresca na sua memória quando concebeu a novela. Esta pareceu, no decurso da edição crítica, ser a data correta; porém, novos conhecimentos sobre as representações no Teatro de Ópera em Lisboa levam-nos a saber que L'Africaine constou dos repertórios de todas as temporadas dos anos 1880 naquele palco, o que não permite determinar nenhuma data em concreto. Apenas fazendo fé nas palavras de Pina podemos afirmar que Alves $\mathcal{E}$ C. a terá sido escrito em França, no ano de 1884. Não teve lugar nas páginas da Gazeta embora o autor tenha guardado o original autógrafo. O porquê destas duas circunstâncias, talvez nunca o saibamos, porque entre as muitas informações acerca de Eça de Queirós e da sua obra que o texto de Mariano Pina que a seguir se reproduz nos fornece, não constam os motivos que levaram o autor, ou o dono do jornal, a não publicar o texto, e o cronista não podia saber que Eça iria manter o autógrafo. Acrescente-se que Pina relata o entusiasmo e carinho que Eça teria pelo romance, sentimentos que adensam mais o mistério do abandono do texto.

Acrescenta o correspondente da Gazeta de Notícias esse outro projeto, que de plano não terá passado, imaginado pelo autor de Os Maias: um memorial da sua mocidade, passada em Portugal e da companhia boémia que o acompanhava.

Serve o relatado, e a reprodução da crónica e dos excertos de autoria de Pina, para deslindar algumas dúvidas que, passados 120 anos sobre a morte de Eça de Queirós, ainda se mantinham. São exemplos claros de que cada vez se torna mais imprescindível a preservação digital de periódicos e a possibilidade de pesquisa a distância, fundamentais para a revisão e estabelecimento de circunstâncias menos claras na 
história, cultura e literatura do século XIX, neste caso concreto, dos estudos queirosianos. Por isso, e para isso, Mariano Pina escreveu em 1884 - A LITERATURA PORTUGUESA A AGRADECER.

Gazeta de Notícias, Rio de Janeiro, 12 de Abril de 1884

\author{
Correio de FrançA \\ Paris, 20 de março. \\ Um romancista célebre
}

Vou-lhes falar dum homem que todos os leitores da Gazeta conhecem, e que todos apreciam e admiram muito. Esse mortal vi-o passar há dias, num aprés-midi esplêndido, ao longo do boulevard, sempre magro, sempre pálido, sempre dobrado, de chapéu de coco cor de castanha, monóculo e cão pela trela, como qualquer inglês que na véspera tivesse atravessado o canal. O cão é pequeno e atarracado, focinho cor de chocolate e olho inteligente - verdadeiro cão de raça.

Tem um irmão, propriedade da Princesa de Gales, que ainda há bem pouco tempo obteve medalha de ouro numa exposição de Londres. Não lhe deram mais honrarias e prebendas - simplesmente porque era cão. José Maria pagou o mano deste alto personagem por um bom par de guinéus. É um animal formosíssimo. Chama-se Don José. Algumas vezes tive a honra de trazer Don José pela trela. O sucesso deste quadrúpede em pleno Paris era deveras assombroso. Nos boulevards parava-se para o verem passar. Nos cafés e nos restaurantes as mulheres levantavam-se para o ver; e as cocottes do café da Paz ofereciam-lhe amorosamente bocaditos de açúcar, que $D$. José comia sobre a palma de uma mão pequenina, rosada e fresca com perfume de heliotrópio...

O homem de quem lhes vou falar, chama-se efetivamente José Maria; mas José Maria é o nome de que apenas se servem os amigos, aqueles a quem ele trata por você. No Brasil e em Portugal o seu nome de guerra é outro; é outro o nome que lhe deu a celebridade, a grande celebridade que hoje tem. 
Para o público este magro e este nevrótico chama-se - Eça de Queirós.

Eça de Queirós passou há dias em Paris, seguindo pouco depois para Angers. Razões de saúde obrigam-no a deixar Bristol, onde é cônsul de Portugal, e a vir procurar, numa província francesa, um clima mais doce e mais benéfico.

Foi o seu sistema de trabalho que lhe arruinou em parte a saúde. Ainda conheci Eça de Queirós em Lisboa, levantando-se às três da tarde, almoçar, e trabalhar até à uma hora da noite. Escrevia ele então Os Maias, o seu novo romance em dois volumes, o primeiro já impresso e brochado em casa de Chardron, mas que só aparecerá acompanhado do segundo, em outubro ou novembro deste ano.

À uma hora da noite, quando as ceias finalizavam nos gabinetes do $\mathrm{Au}$ gusto, é que Eça entrava silenciosamente - para jantar! Numa sala especial do restaurante apareciam regularmente Bordalo Pinheiro, Batalha Reis, Jaime de Séguier, Urbano de Castro, Moura Cabral, e outros. José Maria acendia de novo as palestras e encomendava pratos. Punha o monóculo todas as vezes que ia interromper, e deixava-o cair para comer um bocado de beef. E muitas manhãs às quatro, às cinco e às seis horas, ainda ele nos contava como é que teve uma cena de pugilato com o seu maior amigo, o falecido conde de Resende, no vértice duma pirâmide do Egipto...

Os médicos, vendo-o um tanto anémico e um tanto dispéptico, aconselharam-lhe que abandonasse semelhantes hábitos de vida, para não abreviar a existência.

Eça de Queirós voltou para a Inglaterra e resolveu acabar com os jantares às 2 da madrugada. Passou a usar o regímen inglês. Levantar cedo, comer cousas sãs, e fazer bastante exercício. Chegou a haver uma época em Bristol, em que o homem mais inglês que havia em toda a cidade e em cinco léguas em redondo era Eça de Queirós!

Aparecia em todas as corridas, em todas as regatas, em todos os torneios de lawn tennis e de velocípede. Passou a ter um respeito profundíssimo pelo seu estômago. Abandonou o álcool, adotou o leite, usava do melhor queijo, da melhor manteiga e dos melhores vinhos; fumava pouco, e quando ia jantar, confessou-mo ele, entrava num bar, dos que têm orgulho em expor as carnes na sala pública, onde há um grande braseiro 
e onde a cozinha se faz à vista do freguês - e era ele próprio que ia escolher o pedaço de carne que havia de entrar no jogo. Regímen de primeira ordem. Nada de cozinha francesa - "desta peste dos molhos falsificados, das sopas feitas dos restos da véspera e dos perus de cartão. Comida sã, sãzinha como só se encontra em Inglaterra.” Eça de Queirós, submetido por vontade própria a tão salutar quanto profícuo regímen, imaginava-se, dentro de um ano, um prodígio de saúde e de força física.

Resultado da vida nova, da vida regulada, equilibrada, da vida inglesa enfim - uma nevrose no estomago!

E voltou de novo para a cozinha e para o clima de França! É do céu, do leite, da carne e do vinho de Angers que hoje dependem algumas obras primas que Eça há-de escrever, apenas melhore. Se Os Maias ainda aparecem este ano, tem de ser enviado às margens do Loire o seguinte cartão

\section{A LITERATURA PORTUGUESA}

\section{A AGRADECER}

Um dos muitos pontos de afinidade de Eça de Queirós com Flaubert é o tempo que ele consome na construção dum romance. Eça de Queirós é imensamente espontâneo, trabalha todos os dias, mas só apresenta um livro de anos a anos.

Cada capítulo dos seus romances é feito dum jato. Mas o artista, que tem um grande respeito pela forma, emenda e altera constantemente uma descrição, uma frase, uma palavra. Depois, a sua ideia, que a princípio se poderia indicar como um ponto negro numa grande página, alastra-se, alastra-se como um pingo de azeite numa folha de papel, e dum capítulo sai às vezes um outro romance, e dum romance saem às vezes três. É este trabalho insano e horrível, é esta luta constante pela perfeição sublime das suas obras, que lhe consome um tempo incalculável, e é deste modo que Os Maias anunciados há já três anos só aparecerão em fins de 84 ou princípios de 85 .

Presentemente, Eça de Queirós tem quase terminado um outro romance, que ele destina para a Gazeta de Notícias, romance que prometeu em 1882 em Paris ao nosso redator em chefe Ferreira de Araújo, e que tem por título - Alves $\mathcal{E}$ Companhia. 
Os escritores com os seus livros são positivamente como os pais: - há os filhos preferidos, aqueles a quem votam mais amor e mais simpatia. Eça de Queirós tem-me dito várias vezes, em momentos de expansão literária: - «Aquele Padre Amaro!...» como certos pais cheios de regozijo:

- O Chico! Aquilo é que há-de ser um homem às direitas!...

O Crime do Padre Amaro é a sua obra querida, a sua obra predileta, a obra onde ele deixou pedaços da sua alma de artista. Do Alves $\mathcal{E}$ Companhia falou-me agora também com muito entusiasmo. É um romance pequeno, rápido, mas escrito simplesmente, com uma grande felicidade de tipos, de ação e de estilo.

Em outro livro pensa agora Eça de Queirós: a história da sua vida de rapaz, do seu tempo da universidade, da sua vida na província e na capital, do período de boémia literária, a que andavam ligados Antero de Quental, Oliveira Martins, Batalha Reis e outros.

Esse livro para exatamente no momento em que o homem deixou de colaborar nas Farpas, para colaborar no Diário do Governo; de escrever artigos humorísticos para escrever relatórios sobre a emigração da Havana e sobre a excelência do carvão de Newcastle.

A verdade manda Deus que se diga! Eça de Queirós é considerado pelo mundo oficial como o melhor dos cônsules; e Portugal hesita sobre se lhe há-de levantar uma estátua como cônsul modelo, ou como modelo dos seus romancistas...

Eis os trabalhos que Eça de Queirós tem hoje em preparação:

Alves $\mathcal{E}$ Companhia, romance que deve ser publicado em folhetins pela Gazeta de Notícias.

Quando nós éramos novos, livro de recordações, a mocidade alegre de um artista, narrada por esse mesmo artista.

Presentemente em Angers revê as provas dos Maias e retoca os últimos capítulos.

E creio que ele ainda não abandonou a ideia de escrever um volume de contos singelos, no género dos contos ingleses de Dickens, mas coloridos com o estilo moderno, com o estilo francês - de que Eça possui o segredo em tão elevado grau, e que teria feito dele um dos primeiros romancistas da raça latina, se, em vez de oriundo da Póvoa de Varzim, ele tivesse nascido em terreno gaulês. 
Outrora, os artistas privilegiados e felizes, os que tinham público no seu país e fora dele, eram os músicos, os pintores e os escultores. A sua arte não tinha que estar acorrentada às restrições de uma língua - era uma arte universal. Hoje, os homens já sabem ler, e a esses artistas felizes juntam-se outros - os escritores franceses, que escrevendo em Paris, encontram público nos confins da Rússia e nos confins da América. Atualmente, escrever um romance em francês equivale a pintar sobre uma tela ou a compor uma ópera. Todos o leem e todos o compreendem.

Dizem pessoas graves que uma língua universal é uma bela utopia, como utopia é a República Universal, cantada por Victor Hugo. A tal República pode ser uma utopia; mas a tal língua torna-se uma necessidade imperiosa. Seja o francês, o inglês ou o alemão a língua universal, pouco me importa.

O que se quer, e o que as necessidades da civilização exigem, é que haja uma língua universalmente adotada, como há um sistema universal de pesos e medidas; o que se quer é que haja uma só língua, como um dia há-de haver uma só moeda; o que se quer, é que as literaturas dos pequenos países não sejam eternamente prejudicadas pela invasão e pelo predomínio das grandes literaturas da Europa; o que se quer, é que um livro que se escreva no Rio de Janeiro, encontre leitores em Paris, em Londres ou em Berlim; o que se quer, finalmente, o que se pede e o que se reclama em nome da justiça e em nome da igualdade, é que haja uma só língua, que aos livros suceda o mesmo que às garrafas de Porto, que, apesar do vinho ser do mais puro português, nem por isso deixa de ter amadores em todos os países do mundo onde se bebe, e do mundo onde se sabe beber.

Se nós hoje gozássemos dos benefícios incalculáveis duma língua universal, Eça de Queirós seria um dos romancistas em maior voga, um romancista talvez de maior sucesso que Zola.

Ainda há pouco tempo estive relendo o Primo Basílio, livro que eu não abria ia para três anos, e confesso-lhes que encontrei um sabor estranho, um outro sabor inteiramente à parte de tudo o que tinha lido nestes últimos tempos em França. Eça de Queirós, quando quer ser impessoal, tem nos seus descritivos a mesma forma de colorido, a mesma intensidade de luz e de som que Zola nos seus grandes romances como o Assomoir, a Naná ou o Bonheur des Dames. 
Quando o artista quer ser um delicado e um nervoso; quando a sua prosa tem de ser repassada de sentimento humano; quando tem que adivinhar as lágrimas e sorrisos de sofrimento esvoaçando nos lábios descorados de alguém que é mártir: Eça de Queirós encontra as mesmas imagens, as mesmas expressões, as mesmas espontaneidades de Flaubert e de Daudet. E quando o artista quer torturar o seu estilo, quando quer encontrar a comparação original e a figura extravagante, eu fico sem saber muitas vezes se estou lendo uma das boas páginas de prosa de Júlio Goncourt, ou alguma poesia de Baudelaire.

É um artista de primeira água, um artista que, se escrevesse em Paris, teria enriquecido o editor Charpentier, e ter-se-ia pago um soberbo palacete na avenida Villiers, ao lado de Alexandre Dumas, e uma soberba casa de campo em Maley, ao lado de Victorien Sardou.

Escrevendo em português, o editor dá-lhe largamente para ele pagar o papel que consumiu com os seus romances. Eça de Queirós chegou ao mais que se pode chegar em Portugal! - a não ter contas atrasadas na papelaria!

Ora seja pelo divino amor de Deus!...

O carnaval em Paris é hoje, hoje que é dia da mi-carême. Toda a gente desce para os boulevards, onde devem aparecer grandes mascaradas que se anunciam pelos jornais há cerca de duas semanas. É para ali que eu vou também, para, daqui a quatro dias, lhes poder contar o que é um entrudo em Paris.

\section{Mariano Pina}

RECEBIDO: 08/01/2021 APROVADO: 01/06/2021.

\section{REFERÊNCIAS}

GROSSEGESSE, Orlando. O animal filosófico e a escrita autobiográfica. De E. T. A. Hoffmann a Eça de Queiroz. Runa - revista portuguesa de estudos germanísticos, 1991. 
GROSSEGESSE, Orlando. Animais. Dicionário de Eça de Queirós. Lisboa: Imprensa Nacional - Casa da Moeda, 2015.

LUCA, Tania Regina de. Correspondente no Brasil: Origens da atividade nas décadas de 1870 e 1880, Sur le journalisme, About journalism, Sobre jornalismo. Vol 5, $\mathrm{n}^{\circ} 1$ - 2016. Disponível em: www. surlejournalisme. com/ver Acesso EM: 20 dezembro 2020.

LUCA, Tania Regina de. A Ilustração(Paris, 1884-1892) ea Revista de Portugal (Porto, 1889-1892): diálogos entre projetos editoriais e possibilidades técnicas. In TOPOI, Rio de Janeiro, v. 18, n. 34, p. 91-115, jan/abr 2017. Disponível em: $w w w$. revistatopoi.org Acesso em 20 dezembro 2020.

LUCA, Tania Regina de. A Ilustração (1884-1892): circulação de textos e imagens entre Paris, Lisboa e Rio de Janeiro. São Paulo: UNESP, 2018.

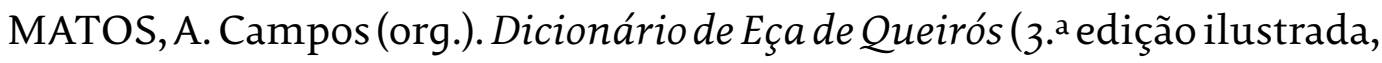
revista e ampliada). Lisboa: Imprensa Nacional - Casa da Moeda, 2015.

MINÉ, Elza. Mariano Pina, a Gazeta de Notícias e a Ilustração: histórias de bastidores contadas pelo seu espólio. Revista da Biblioteca Nacional, julho-dezembro de 1992, p. 23-61.

MOREAU, Mário. O teatro de S. Carlos: Dois Séculos de História. Lisboa: Hugin Editores, 1999. $2 \mathrm{v}$.

QUEIRÓS, Eça de. Alves E C.a . Edição crítica: Luiz Fagundes Duarte e Irene Fialho. Lisboa: Imprensa Nacional - Casa da Moeda, 1994.

QUEIRÓS, Eça de. Correspondência. Organização e notas de A. Campos Matos. Lisboa: Caminho, 2008. 2 v.

QUEIRÓS, Eça de. Almanaques e outros dispersos. Edição crítica: Irene Fialho. Lisboa: Imprensa Nacional - Casa da Moeda, 2011.

REIS, Carlos. Duas cartas inéditas de Eça de Queirós a Mariano Pina. Colóquio-Letras, n. ${ }^{\circ}$ 109, maio-junho 1989, p. 77-82

\section{MinicurRículo}

Irene Fialho tem-se dedicado ao estudo da vida e obra de Eça de Queirós. Publicou na Imprensa Nacional, no âmbito da Edição Crítica da Obra do autor, os volumes Alves E Cia. (1994, com Luiz Fagundes Duarte), Almanaques e outros dispersos (2011) e A correspondência de Fradique Mendes (2014, com Carlos Reis e Maria João Simões). Preparou para a Biblioteca Nacional de Portugal Almanaques (2001) e Aquisições Queirosianas (2007). 
Em 2013 publicou a opereta inédita de Eça de Queiroz, Jaime Batalha Reis e Augusto Machado, A morte do Diabo e, em 2016, o volume de inéditos Eça de Queiroz em Casa. Pertence ao Conselho Cultural da Fundação Eça de Queiroz desde 2002 e foi vogal do Conselho de Administração da mesma instituição entre 2010 e 2020. É membro do Instituto de Estudos de Literatura Tradicional da Universidade Nova de Lisboa, do Centro de Literaturas e Culturas Lusófonas e Europeias da Universidade de Lisboa e do Centro de Literatura Portuguesa da Universidade de Coimbra. 